\title{
Determination of the Change of the Dissolved Oxygen Content after Silicon Deoxidation by the Use of Radioactive Silicon*
}

\author{
By Rokuro SAKAGAMI** and Takashi SASAI**
}

\section{Synopsis}

The changes of the dissolved oxygen content after deoxidation with $0.1 \%$ and $0.42 \%$ silicon were determined by fixing the oxygen as radioactive silica with radioactive silicon (silicon-31) previously charged in a sampler and by counting the radioactivity of the residue extracted from the taken sample.

In both cases, the dissolved oxygen content decreased with time rapidly below the equilibrium value, reaching a minimum, then increased gradually until equilibrium was established.

The mechanism of the silicon deoxidation has been discussed from the viewpoint that such change of the dissolved oxygen content is due to the non-uniform distribution of silicon built up in the melt immediately after silicon addition and to the formation of $\mathrm{SiO}_{x}(x<2)$ in the region of high silicon content. The minimum oxygen content after silicon addition corresponds to the average oxygen content at the time when silicon, oxygen and deoxidation product have been distributed uniformly throughout the melt.

The dissolved oxygen content is hereafter increased by the reaction $\mathrm{SiO}_{2}$ (crucible $)=\underline{\mathrm{S}}+2 \mathrm{O} . \quad$ Also, the processes such as the growth of the deoxidation product, $\mathrm{SiO}_{x}$, and the adhesion of it to the crucible wall, in other words, the deoxidation process is rate-controlled by the rate of the above reaction.

$\mathrm{SiO}_{x}$ is not widely different from silica in composition.

\section{Introduction}

In the previous investigation carried out to determine the dissolved oxygen content after silicon deoxidation by the Herty method, ${ }^{1)}$ the deoxidized melt was shown to be superficially supersaturated with oxygen until equilibrium was established. This was explained to be the consequence of the rapid reduction of the very fine deoxidation product with aluminium during solidification of the taken sample. The purpose to determine the dissolved oxygen content was, in conclusion, left unaccomplished.

In this experiment, further attempt was made to determine the dissolved oxygen content by utilizing radioactive silicon, based on the similar principle and procedure to those employed in the previous investigation.

The determination of the dissolved oxygen content by the use of radioactive silicon was carried out by Y. Miyashita. ${ }^{2)}$ According to his report, the dissolved oxygen content decreased rapidly to a certain value in about $1 \mathrm{~min}$ after silicon deoxidation and hereafter remained nearly constant. However, the result seems to be questionable in the following respects:

(1) The change of the dissolved oxygen content with time given in his paper was determined by compiling data obtained in separate heats for which the time of addition of radioactive silicon was changed.
It is much preferable to perform the determination in a single heat.

(2) He assumed that the amount of radioactive silica floating out of liquid iron during the period of about $40 \mathrm{sec}$, which was required for uniform dissolution of radioactive silicon, was negligibly small. This assumption, however, is quite doubtful in the deoxidation experiment.

(3) His results are supposed to have been greatly influenced by the replacement reaction taking place between very fine deoxidation product and radioactive silicon dissolved in the melt.

In the present experiment, particular attention was paid to resolve these problems.

\section{Experimental}

The principle for determining the dissolved oxygen content after silicon deoxidation is to fix a fraction of it as radioactive silicon oxide with radioactive silicon previously charged in a silica sampler and to measure the radioactivity of the resulting residue extracted from the taken sample. ${ }^{3,4)}$ (Fig. 1)

At suitable intervals after silicon addition, the bottom part of the sampler in which the predetermined amount of radioactive silicon was previously charged was dipped into the melt for $7 \mathrm{sec}$. After melt down of radioactive silicon, the sampler was further dipped into the melt to sample about $10 \mathrm{~g}$ of the melt into it through an opening of $5 \mathrm{~mm}$ dia. and then quenched in water at once. Radioactive silicon, like aluminium in the previous work, dissolved uniformly in the sample in a short time.

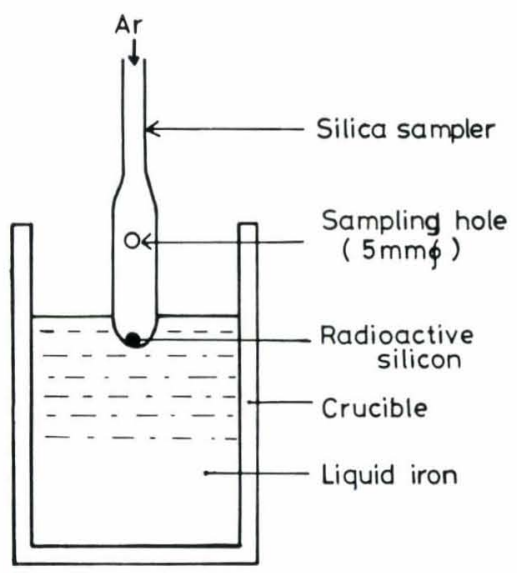

Fig. 1. Silica sampler in which radioactive silicon is previously charged

* Originally published in Tetsu-to-Hagané, 62 (1976), 1189, in Japanese. English version received February 4, 1977.

** The Research Institute for Iron, Steel and Other Metals, Tohoku University, Katahira, Sendai 980. 
The radioactive silicon used in this experiment was produced by irradiating metallic silicon of adequate purity $(99.999 \%$ ) for $20 \mathrm{~min}$ in a nuclear reactor generating a neutron flux of $7 \times 10^{13} \mathrm{n} / \mathrm{cm}^{2} \cdot \mathrm{sec}$. The radioactivity immediately after the irradiation was $12 \mathrm{mCi} / \mathrm{g}$-silicon.

2 to $5 \mathrm{~g}$ of the samples were dissolved mainly in hot $\left(80^{\circ} \mathrm{C}\right)$ dilute sulphuric acid $\left(1 \mathrm{H}_{2} \mathrm{SO}_{4} / 9 \mathrm{H}_{2} \mathrm{O}\right)$ and then the solution was passed through a membrane filter having a pore diameter of $0.4 \mu$. After ashing of the filter and residue, the residue was suspended in water and the suspension was once more passed a membrane filter having a filtration area of $0.5 \mathrm{~cm}^{2}$ to disperse the residue uniformly on it. The central portion of a stainless steel filter holder between which the membrane filter was interposed were dried, then placed in a holder of a Geiger-Müller counter. The measurement of radioactivity was carried out at $25 \mathrm{~min}$ interval over $2 \mathrm{hr}$ to examine the half-life period. The counting rates were usually 1000 to $10000 \mathrm{cpm}$.

Furthermore, in order to eliminate the influence of self-absorption on the determination, the sample weight used for dissolution was determined with reference to the change in the total oxygen content of the melt so that the weight of the residue extracted from each sample was nearly constant in one experiment. In Fig. 2 are shown the changes in silicon and oxygen contents and solubility product $[\% \mathrm{Si}] \cdot[\% \mathrm{O}]^{2}$ for electrolytic iron melt which was held at $1600^{\circ} \mathrm{C}$ in silica crucible. As evident from the figure, oxida-

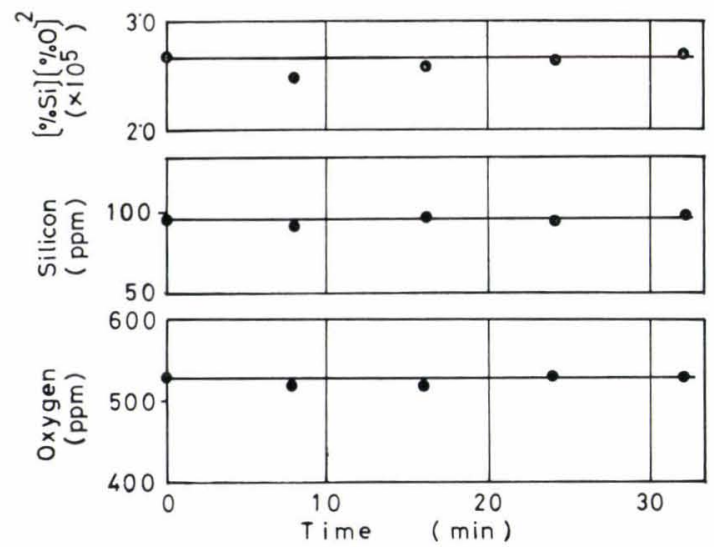

Fig. 2. Oxygen and silicon contents and $[\% \mathrm{Si}] \cdot[\% \mathrm{O}]^{2}$ of electrolytic iron melt which is kept at $1600^{\circ} \mathrm{C}$ in a silica crucible tion of the iron melt by furnace atmosphere is negligibly small. Also, observed solubility product of $2.6 \times 10^{-5}$ indicates that equilibrium is established between the melt and crucible.

By the use of the silica sampler shown in Fig. 1, the problems involved in Miyashita's experiment are regarded as being almost solved in this experiment, because (1) the change of the dissolved oxygen content can be obtained in a single heat, (2) the amount of radioactive silica floating out of the taken sample is negligibly small and (3) the replacement reaction of silicon between radioactive silicon and deoxidation product is minimized with the aid of rapid cooling of the taken sample.

\section{Calculation of the Dissolved Oxygen Content}

For the calculation of the dissolved oxygen content, it has been assumed that (1) the doxidation product formed after silicon addition is regarded as silica and (2) all of oxygen dissolved in the deoxidized melt precipitates as silica during solidification of the taken sample. (Table 1)

When the equilibrium state after silicon deoxidation is chosen as a standard, the equations for the calculation are given as follows:

$$
\begin{aligned}
I_{t} & =K \frac{28}{32} \frac{W_{t} \mathrm{O}_{t}}{100} \frac{* \mathrm{Si}_{t}}{\mathrm{Si}_{t}+* \mathrm{Si}_{t}} \\
I_{e} & =K \frac{28}{32} \frac{W_{e} \mathrm{O}_{e}}{100} \frac{* \mathrm{Si}_{e}}{\mathrm{Si}_{e}+* \mathrm{Si}_{e}} \\
\mathrm{Si}_{t} & =\mathrm{Si}_{i}+\mathrm{Si}_{d}-\frac{28}{32}\left(\mathrm{O}_{i}-\mathrm{O}_{t}\right) \ldots \\
\mathrm{Si}_{e} & =\mathrm{Si}_{i}+\mathrm{Si}_{d}-\frac{28}{32}\left(\mathrm{O}_{i}-\mathrm{O}_{e}\right) \ldots
\end{aligned}
$$

where, $\quad I_{t}$ : counting rate obtained for the extraction residue from $W_{\iota} \mathrm{g}$ sample taken at time $t$ after silicon addition (cpm)

$I_{e}$ : counting rate obtained for the extraction residue from $W_{e} \mathrm{~g}$ sample taken at equilibrium (cpm)

$W_{\iota}, W_{e}:$ sample weight dissolved $(\mathrm{g})$

$* \mathrm{Si}_{t}, * \mathrm{Si}_{e}:$ amount of radioactive silicon previously charged in sampler for the sampling at time $t$ or at equilibrium $(\mathrm{wt} \%)$

$\mathrm{Si}_{t}, \mathrm{Si}_{e}$ : dissolved silicon content at time $t$

Table 1. Comparison of the oxygen content of the sample obtained by the gas analysis with that calculated from the silicon content of the extracted residue

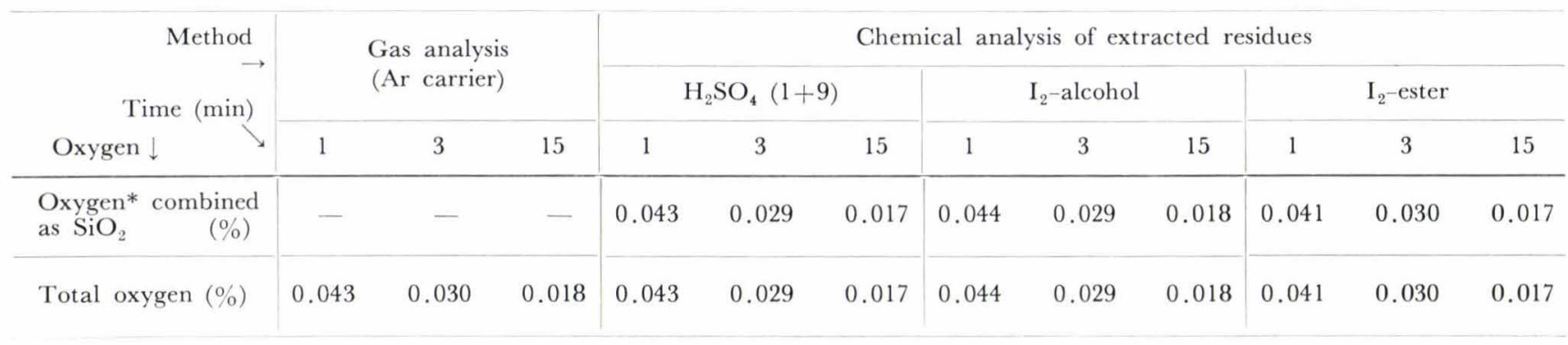

* Oxygen combined as $\mathrm{FeO}$ is trace. 
or at equilibrium $\left(\mathrm{wt}^{\mathrm{o}} \%\right)$

$\mathrm{Si}_{i}$ : initial silicon content $(\mathrm{wt} \%)$

$\mathrm{Si}_{d}:$ added amount of silicon ( $\mathrm{wt} \%$ )

$\mathrm{O}_{\iota}, \mathrm{O}_{e}$ : dissolved oxygen content at time $t$ or at equilibrium $\left(\mathrm{wt}^{\mathrm{o}} \%\right)$

$\mathrm{O}_{i}$ : initial oxygen content $(\mathrm{wt} \%)$

28/32: weight ratio of silicon to oxygen contained in silica

$K$ : experimental constant involving specific activity of radioactive silicon, counting efficiency of the used Geiger-Müller counter, etc. $\left(\mathrm{cpm} \cdot \mathrm{g}^{-1}\right)$

Since the values of $I_{t}, I_{e}, \mathrm{Si}_{e}, * \mathrm{Si}_{t}, * \mathrm{Si}_{e}$ and $\mathrm{O}_{e}$ are known, $\mathrm{O}_{t}$ can be derived by using the above four equations.

When the initial state before deoxidation is chosen as a standard, $\mathrm{O}_{\iota}$ can be obtained by the use of Eqs. (1), (3) and (5), if a sample is taken from the initial melt according to the above-mentioned procedure:

$$
I_{i}=K \frac{28}{32} \frac{W_{i} \mathrm{O}_{i}}{100} \quad{ }^{*} \mathrm{Si}_{i}+* \mathrm{Si}_{i}
$$

where, $I_{i}$ : counting rate obtained for the extraction residue from $W_{i} \mathrm{~g}$ sample taken before silicon addition (cpm)

$* \mathrm{Si}_{i}$ : amount of radioactive silicon previously charged in sampler $\left(\mathrm{wt}^{\mathrm{O}} \%\right)$

$W_{i}$ : sample weight dissolved $(\mathrm{g})$

Difference due to the choice of either of the two standards was not significant, hence the equilibrium state was used usually as a standard.

\section{Results}

\section{Change of Counting Rate with Time and Precision of Determination}

Irradiating metallic silicon in a nuclear reactor also produces the radioisotopes of impurities such as aluminium, calcium, manganese and iron, even though the amount of these product is negligibly small or the radioactivity of them decays in a short time. In order to examine the influence of these radioactive impurities, the measurement of radioactivity was continued at least for $2 \mathrm{hr}$. In Figs. 3 (a) and (b) are shown the decay curves for the residues extracted from the samples which were taken after deoxidizing the electrolytic iron melt with $0.1 \%$ and $0.42 \%$ silicon. From these results, the half-life period was determined to be $2.62 \mathrm{hr}$ which agrees with that of radioactive silicon ${ }^{31} \mathrm{Si}$. It is apparent, therefore, that all of the radiation measured by a Geiger-Müller counter is $\beta$ ray emitted during the decay of ${ }^{31} \mathrm{Si}$.

Figure 4 shows the oxygen contents of the equilibrium melts of various silicon contents obtained by the radiochemical method, compared with that obtained by the ordinary gas analysis. Both agree well with one another. Furthermore, the determination of the dissolved oxygen content was carried out two or three times for each case in this experiment, but variation was small as shown in Figs. 5 to 7 . From these results, it may be concluded that the precision of the determination is at most $\pm 5 \mathrm{ppm}$.

\section{Change of the Dissolved Oxygen Content}

In Fig. 5 are shown the changes of the dissolved and the total oxygen contents after $0.1 \%$ silicon addition into the melt which was held at $1600^{\circ} \mathrm{C}$ in silica crucible. The amount of radioactive silicon was in the range of $0.04 \%$ to $0.07 \%$. The total oxygen content decreased slowly and reached the equilibrium value at about $6 \mathrm{~min}$ after silicon addition, while the dissolved oxygen content decreased rapidly to about $150 \mathrm{ppm}$, then increased slowly to reach equilibrium also in about $6 \mathrm{~min}$. In Fig. 5 are summarized the results obtained by using dilute sulphuric acid $\left(1 \mathrm{H}_{2} \mathrm{SO}_{4} /\right.$ $\left.9 \mathrm{H}_{2} \mathrm{O}\right)$, dilute nitric acid $\left(1 \mathrm{HNO}_{3} / 3 \mathrm{H}_{2} \mathrm{O}\right)$ or iodinealcohol solution $\left(7 \mathrm{~g} \mathrm{I}_{2} / 50 \mathrm{cc} \mathrm{CH}_{3} \mathrm{OH}\right)$ for the dissolution of sample. The influence of the dissolution method, however, is not observed.

Figure 6 shows the results after $0.1 \%$ silicon addition at $1600^{\circ} \mathrm{C}$, obtained by changing the charged amount of radioactive silicon at three levels of about $0.05,0.15$ and $0.5 \%$. The influence of the charged amount is not observed too.

Figure 7 shows the results after $0.42 \%$ silicon addi-

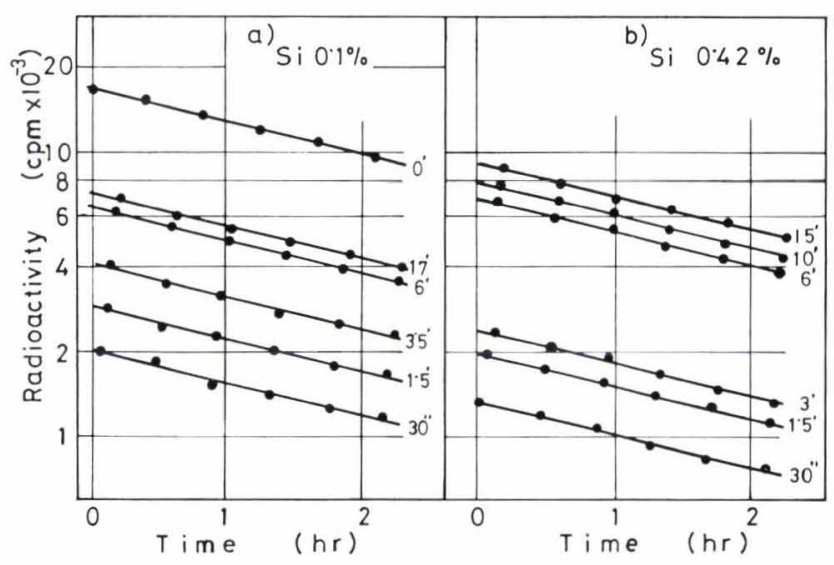

Fig. 3. Changes of the radioactivity of the extracted residues with time

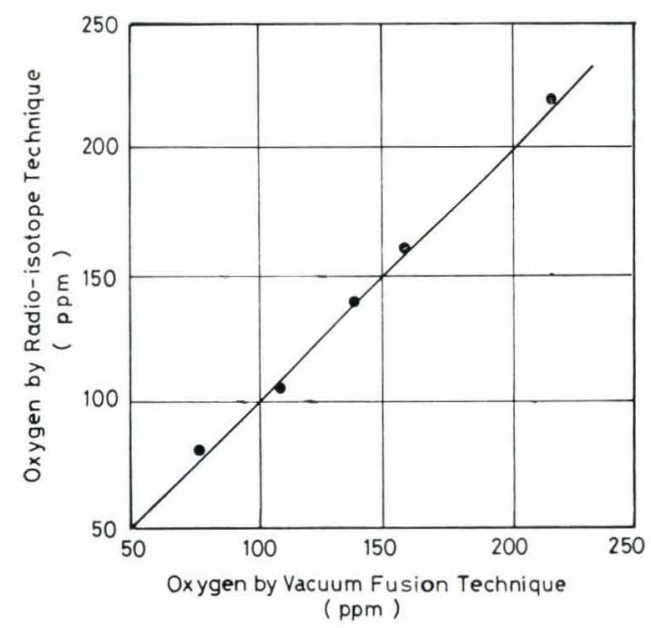

Fig. 4. Comparison of the oxygen content of iron melt determined by radioisotope technique with that obtained by gas analysis 


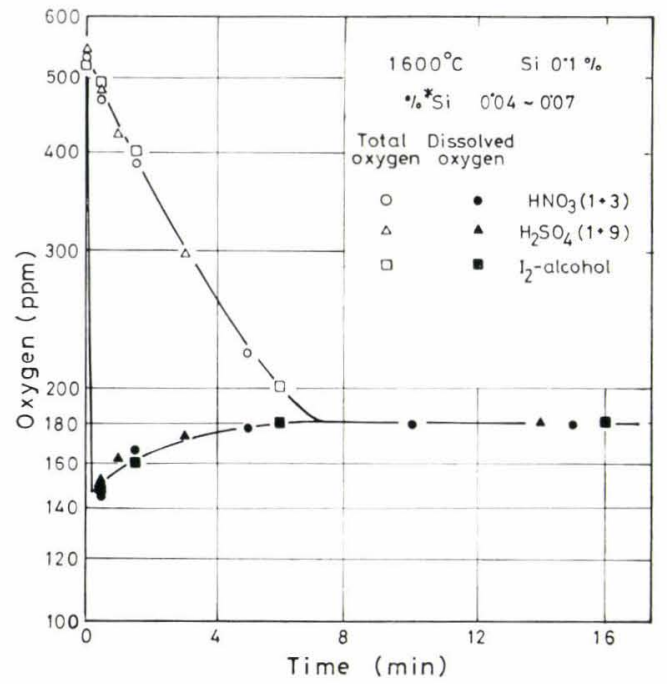

Fig. 5. Changes of the dissolved and the total oxygen contents with time after $0.1 \%$ silicon addition at $1600^{\circ} \mathrm{C}$. The results obtained by using dilute $\mathrm{HNO}_{2}, \mathrm{H}_{2} \mathrm{SO}_{4}$ and $\mathrm{I}_{2}$-alcohol solution for the dissolution of sample are shown together in the figure.

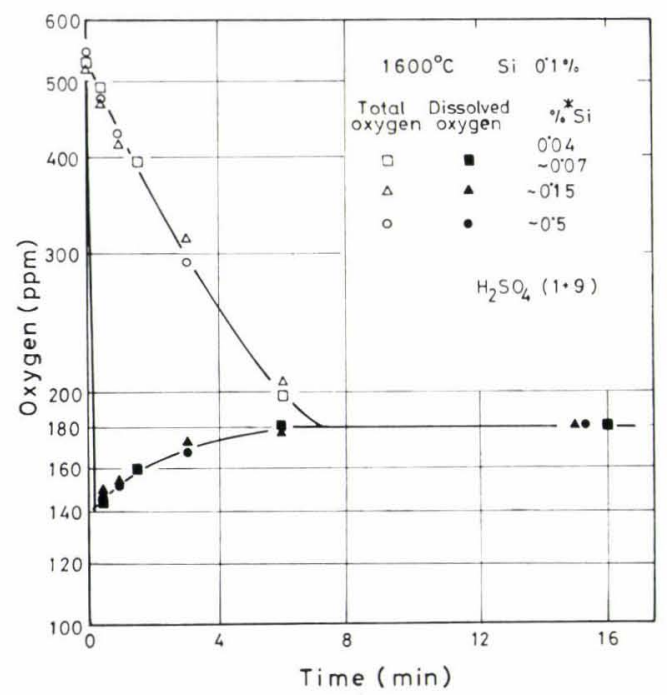

Fig. 6. Changes of the dissolved and the total oxygen contents with time after $0.1 \%$ silicon addition at $1600^{\circ} \mathrm{C}$. Effect of the charged amount of radioactive silicon is shown.

tion at $1600^{\circ} \mathrm{C}$. The charged amount of radioactive silicon was here changed at three levels of about $0.12,0.2$ and $0.4 \%$. The dissolved oxygen content decreased rapidly to about $65 \mathrm{ppm}$, and then increased to reach equilibrium at about $10 \mathrm{~min}$ after silicon addition, while the total oxygen content decreased slowly and reached equilibrium also in about $10 \mathrm{~min}$.

From the above results, it is found that the dissolved and the total oxygen contents reach the equilibrium value at about the same time which depends on the amount of silicon initially added to liquid iron. Further, equilibrium is found to be established sooner for $0.1 \%$ silicon addition than for $0.42 \%$ silicon addition.

In Figs. 8 (a) and (b) are shown the changes of

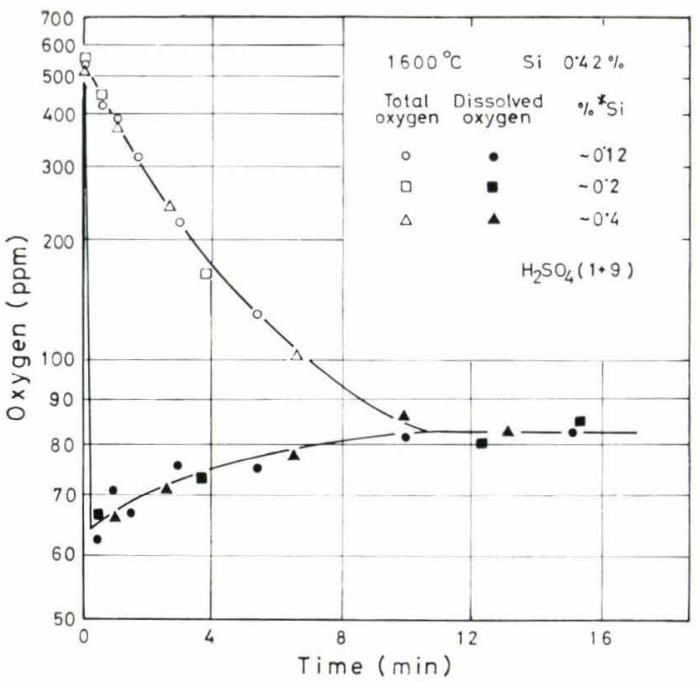

Fig. 7. Changes of the dssolved and the total oxygen contents after $0.42 \%$ silicon addition at $1600^{\circ} \mathrm{C}$

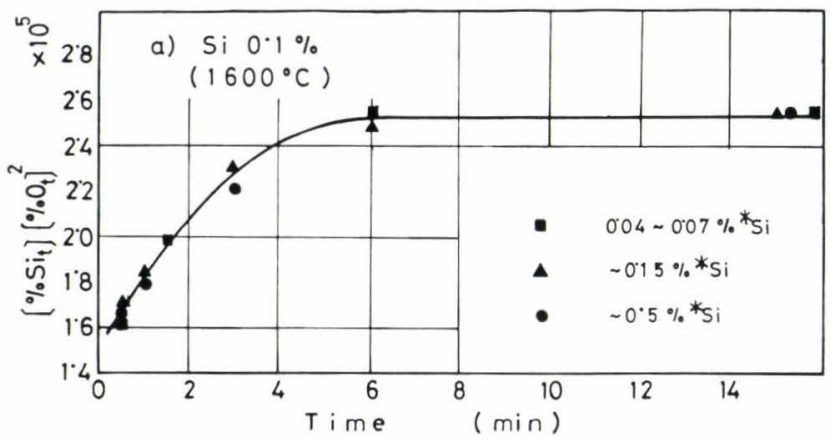

Fig. $8(\mathrm{a})$. Change of the solubility product $\left[\% \mathrm{Si}_{t}\right] \cdot\left[\% \mathrm{O}_{t}\right]^{2}$ after $0.1 \%$ silicon addition

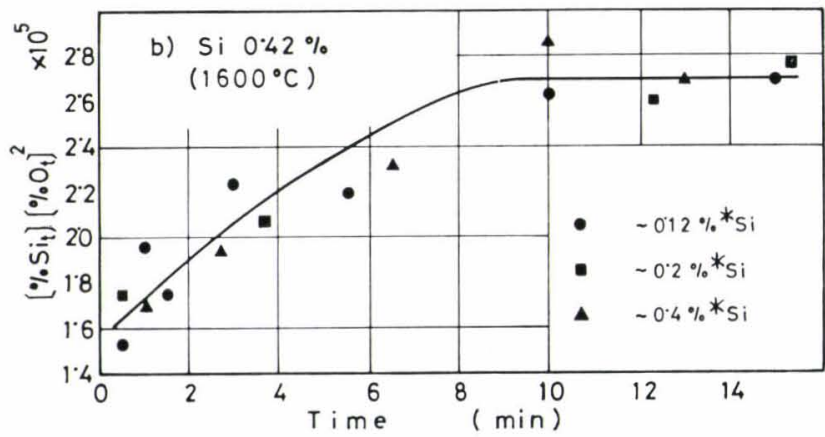

Fig. $8\left(\right.$ b). Change of the solubility product $\left[\% \mathrm{Si}_{t}\right] \cdot\left[\% \mathrm{O}_{t}\right]^{2}$ after $0.42 \%$ silicon addition

the solubility products $\left[\% \mathrm{Si}_{t}\right] \cdot\left[\% \mathrm{O}_{t}\right]^{2}$ after $0.1 \%$ and $0.42 \%$ silicon additions, evaluated from $\mathrm{O}_{t}$ and $\mathrm{Si}_{t}$. The latter was calculated by Eq. (3).

Figure 9 shows the results after $0.1 \%$ silicon addition to the melt which was held at $1600^{\circ} \mathrm{C}$ in alumina $\left(95 \% \mathrm{Al}_{2} \mathrm{O}_{3} / 5 \% \mathrm{SiO}_{2}\right)$ or magnesia $(98 \% \mathrm{MgO} /$ $1 \% \mathrm{CaO}$ ) crucible. The dissolved oxygen content decreased promptly after silicon addition, then increased gradually in a similar manner to that in silica crucible. After about $3 \mathrm{~min}$, however, it decreased again to reach the constant value in $15 \mathrm{~min}$. Thus, the dissolved oxygen content $v s$. time curve for alumina or magnesia crucible clearly exhibited a maximum. 


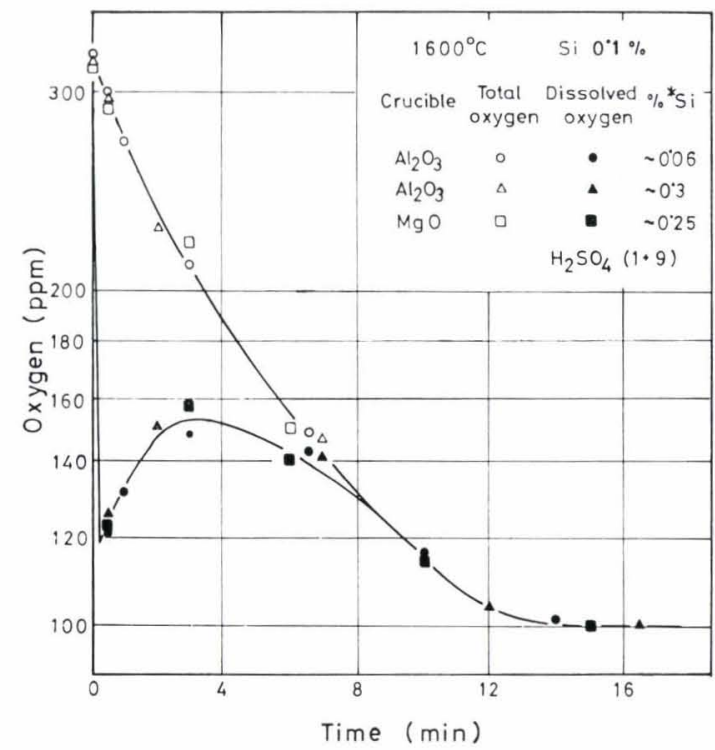

Fig. 9. Changes of the dissolved and the total oxygen contents after $0.1 \%$ silicon addition into iron melt which is kept at $1600^{\circ} \mathrm{C}$ in alumina or magnesia crucible

Figure 10 shows the result after $0.36 \%$ silicon addition to a quasi-static melt which was held at $1600^{\circ} \mathrm{C}$ in alumina crucible. In this experiment, the crucible was placed inside of a graphite container to minimize stirring of the melt due to induction heating. The change of the dissolved oxygen content is similar to the above result for the stirred melt, but much slower than that.

\section{Discussion}

The remarkable feature of the results obtained in this experiment is that the dissolved oxygen content first decreases promptly below the equilibrium value, and then increases gradually until equilibrium is established. Such feature is also found for the change in the oxygen activity of the melt deoxidized with zirconium, ${ }^{5,6)}$ aluminium, ${ }^{7,8)}$ silicon, ${ }^{9,10)}$ manganese ${ }^{11)}$ and calcium-silicon-barium alloy ${ }^{12}$ ) obtained by the electrochemical method using appropriate solid electrolyte, and thus regarded as a general phenomenon encountered with a laboratory scale precipitation deoxidation. For the explanation of such result, it is essential to adopt the following viewpoints:

(1) Assuming that the deoxidation reaction proceeds after uniform dissolution of added silicon into the melt, the minimum oxygen content attained immediately after silicon addition indicates either the equilibrium oxygen content peculiar to this reaction or the oxygen content at the steady state where the rate of the deoxidation reaction is balanced with that of the oxygen transfer from outside. In either case, the oxygen content cannot increase again, because the deoxidation reaction must proceed to consume oxygen transferring hereafter into the melt. Under these circumstances, the above phenomenon can be understood to be due to the non-uniform distribution of silicon in the melt formed by silicon addition. ${ }^{13,14}$ ) Namely, it is necessary to premise that the reaction, by which the oxygen content was decreased promptly

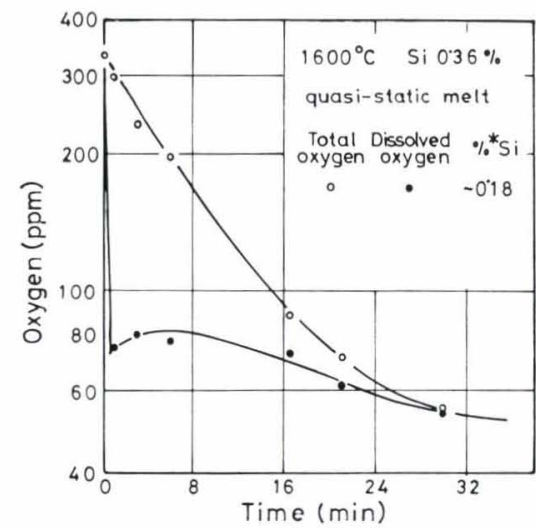

Fig. 10. Changes of the dissolved and the total oxygen contents after $0.36 \%$ silicon addition into quasi-static melt which is kept at $1600^{\circ} \mathrm{C}$ in alumina crucible

below the equilibrium value, is considered to proceed only when silicon dissolves non-uniformly in the melt but no longer takes place after uniform dissolution.

(2) If all of the deoxidation product were silica, the dissolved oxygen content could not decrease below the equilibrium value, because oxygen is supplied rapidly into the melt by the decomposition of silica. Therefore, it is further necessary to postulate that $\mathrm{SiO}_{x}(x<2)$ having a lower oxygen potential than silica is formed in some regions of the melt and the oxygen contents in these regions decrease considerably below the equilibrium values which depend on their silicon contents.

Based on these two prerequisites, the kinetics of the silicon deoxidation will be discussed in the following sections.

\section{The Kinetics of the Silicon Deoxidation}

\section{Formation of $\mathrm{SiO}_{x}(x<2)$ during the Dissolution of Added Silicon}

The silicon content varies in a very complicated manner in each region of the melt until added silicon dissolves uniformly. However, the dissolution process ends in a short time in the present experiment, and hence it would be allowed to discuss the behaviour of the deoxidation reaction in this period qualitatively, noting only to the first stage immediately after silicon addition when the regions of various silicon contents have been built up in the melt and to the final stage when silicon has dissolved uniformly in the melt.

The progress of the deoxidation reaction at the first stage is explained as follows: In the regions of higher silicon content, silicon atoms may rapidly react with oxygen atoms in the immediate vicinity of them, rather than react with exactly twice much oxygen atoms so that the stable product such as silica is formed, because the reaction proceeds at an exceedingly fast rate in these regions. In this instance, it is reasonable to suppose that a large number of $\mathrm{SiO}_{x}(x<$ 2) containing excess silicon relative to silica is formed in the melt, reflecting the situation that the added amount of silicon is usually much larger than the oxygen content of the iron melt. The reaction proceeds 
still rapidly with the formation of $\mathrm{SiO}_{x}$, even if the oxygen content decreases, and at the end of the first stage it falls below the equilibrium oxygen content which depends on the silicon content in each region.

In the regions of lower silicon content, on the other hand, a tendency to form silica becomes predominant on account of the slower rate of the reaction, and the oxygen content decreases towards the equilibrium value.

The deoxidation reactions taking place in each region of the melt at the first stage are expressed as follows:

$$
\underline{\mathrm{Si}}+x \underline{\mathrm{O}}=\mathrm{SiO}_{x} \quad(x \leq 2)
$$

The final stage is the step that silicon, oxygen and deoxidation product have been distributed uniformly throughout the melt. The minimum oxygen content immediately after silicon addition estimated by the extrapolation of the experimental values is regarded as the average oxygen content at this stage. The solubility product $\left[\% \mathrm{Si}_{t}\right] 1\left[\% \mathrm{O}_{t}\right]^{2}$ at this instant then becomes smaller than the equilibrium one, and hereafter reaction (6) no longer takes place.

According to the above view, the first decrease of the dissolved oxygen is expected to be dependent on the method of addition of deoxidizer, the magnitude of motion of the melt and the rate of oxygen transfer into the melt, etc. However, the formation of the non-equilibrium product such as $\mathrm{SiO}_{x}$ in the region highly concentrated with deoxidizing element is taken as a common phenomenon in the deoxidation of the iron melt of high oxygen content. Therefore, it seems likely that the oxygen content decreases, usually in a laboratory scale deoxidation experiment, below the equilibrium value or the steady oxygen content immediately after addition of deoxidizer. The results ${ }^{5-8}$ ) obtained in the zirconium and aluminium deoxidation support this argument.

\section{Growth of the Deoxidation Product and Decrease of the Total Oxygen Content}

After the second stage, silicon and oxygen transfer into the melt mainly from silica crucible, and the dissolved oxygen content increases towards the equilibrium value with the progress of the following reaction:

$$
\mathrm{SiO}_{2}=\underline{\mathrm{Si}}+2 \underline{\mathrm{O}}
$$

During this period, growth of the deoxidation product and separation of it from the melt take place simultaneously, and the total oxygen content decreases gradually towards the equilibrium value.

Now, it is worth noting that the dissolved and the total oxygen contents reach the equilibrium value nearly at the same time which depends on the added amount of silicon (Si $0.1 \%: \sim 6 \mathrm{~min}, 0.42 \%: \sim 10$ min). Taking into account that similar results as such have been obtained also in the deoxidation experiments with other elements, this observation cannot be said to be incidental, but suggests close relation between the processes of growth and separation of the deoxidation product and the increase of the dissolved oxygen content.

In the first place, the growth process will be explained on the basis of this observation. The deoxidation product initially formed in the melt is very small in size as concluded in the previous paper, ${ }^{1)}$ but some fraction of it grows to particles of about $10 \mu$ dia. in 3 min after silicon addition (Although the deoxidation products were regarded as silica in the previous paper, it has been shown here that they were, in fact, $\mathrm{SiO}_{x}$ $(x<2))$.

Because the reaction $\underline{\mathrm{Si}}+x \underline{\mathrm{O}} \rightarrow \mathrm{SiO}_{x}(x \leq 2)$ can not take place after the second stage, such growth is evidently caused by collision between the deoxidation products and coalescence of the products collided with each other. However, taking into account the close relation of the growth process to the increase of the dissolved oxygen content, it is appropriate to express the processes of collision and coalescence by the following equation in which oxygen takes part as a reactant.

$$
\mathrm{SiO}_{x}+y \underline{\mathrm{O}}+\mathrm{SiO}_{x} \rightarrow \mathrm{Si}_{2} \mathrm{O}_{2 x+y}
$$

Reaction (8) also means that the composition of the product moves from $\mathrm{SiO}_{x}$ towards silica with the increase of the dissolved oxygen content, and the outer shell of them, at least, becomes silica when equilibrium has been established.

The products grown to larger sized particles separate successively to the top surface of the melt, but their floating up is not always completed just when the dissolved oxygen content has reached the equilibrium value, because reaction (8) originally does not express floating up itself. That is, if the total oxygen content were decreased only by floating up of the larger sized particles from the melt, it would be impossible to explain the foregoing observation.

This clearly suggests the necessity to take account of the deoxidation due to adhesion of the deoxidation product to the crucible wall as well as floating up. The deoxidation process proceeding at the crucible wall is represented as follows, on the same reason as described for Eq. (8).

$$
\mathrm{SiO}_{x}+(2-x) \underline{\mathrm{O}} \rightarrow \mathrm{SiO}_{2}
$$

Reaction (9) means that adhesion does not occur by simple collision of the deoxidation product with the crucible wall, but happens only when the product, after collision, changes the composition from $\mathrm{SiO}_{x}$ to silica, by absorbing oxygen at the crucible wall.

Attainment of equilibrium of both the total and the dissolved oxygen contents nearly at the same time indicates that reaction (9) almost ends when the dissolved oxygen content has reached the equilibrium value. Furthermore, the sooner completion of separation of the deoxidation product in the case of $0.1 \%$ silicon deoxidation rather than $0.42 \%$ silicon deoxidation is attributed to the earlier attainment of equilibrium in the former case.

In the foregoing explanation, it has been pointed out that oxygen closely concerns with the processes of coalescence and adhesion of the deoxidation product 
and that the rates of these processes depend on the rate of oxygen transfer from silica crucible into the melt.

Now, faster attainment of equilibrium after deoxidation with $0.1 \%$ silicon, despite the larger difference between the minimun and the equilibrium oxygen contents, was already confirmed in the previous investigation on the kinetics of transfer of silicon and oxygen from silica crucible into the melt. ${ }^{15}$ This is a positive confirmation that the above processes, in other words, the deoxidation process is controlled in the stirred melt by the rate of the reaction $\mathrm{SiO}_{2}=\underline{\mathrm{Si}}+$ 2Q.

In has long been believed that the deoxidation reaction came to an end immediately after addition of deoxidizer and thus the rate of decrease in the total oxygen content was determined only by the physical process such as floating up of the deoxidation product. Such conventional viewpoint, however, has been ascertained to be extremely doubtful.

\section{Composition of the Deoxidation Product}

While the composition of the deoxidation product has been tentatively expressed as $\mathrm{SiO}_{x}$ or $\mathrm{Si}_{2} \mathrm{O}_{2 x+y}$, it is discussed here in some detail based on the composition of the inclusion contained in solidified sample.

Compositional difference is expected to be present between the deoxidation product suspended in the iron melt and the inclusion contained in solidified sample on the following grounds.

(1) The most part of the dissolved oxygen precipitates as silica during solidification of sample, because the supersaturation built up in liquid phase during this period is not so large as to form $\mathrm{SiO}_{x}$, especially in the case of rapid solidification. Therefore, the inclusion differs from the deoxidation product in average composition by the amount of the additional silica formed during solidification.

(2) A part of the dissolved oxygen is consumed also by the reactions like $\mathrm{SiO}_{x}+\underline{\mathrm{O}} \rightarrow \mathrm{SiO}_{1+x}$ and $\mathrm{SiO}_{x}+(2-x) \underline{\mathrm{O}} \rightarrow \mathrm{SiO}_{2}$ during solidification. However, the compositional change of the deoxidation product itself due to such reactions is limited only to its surface layer, and hence makes a relatively small contribution to the overall change in composition, except the period immediately after silicon addition where most of the product are very small in size. As to the sample taken at 3 min after silicon addition, for instance, the compositional difference is mainly attributed to the presence of the additional silica formed during solidification. The inclusion contained in the solidified sample is thus regarded as a simple mixture of such secondary silica and the deoxidation product suspended in the melt at this instant.

According to Figs. 5 and 7 , it is considered that the deoxidation product of not less than half of the total inclusion is contained in the sample taken at $3 \mathrm{~min}$. Therefore, the existence of $\mathrm{SiO}_{x}$ must be easily detected, if it is widely different from silica in composition. However, the total oxygen content obtained by the ordinary gas analysis is in fair agreement with that calculated from the silicon content of the extracted residue assuming that the silicon is combined as silica, as shown in Table 1.

It is thus apparent that the deoxidation product at this instant possesses a composition appreciably close to silica. Furthermore, the composition of the deoxidation product immediately after silicon addition cannot be widely different from silica, because the amount of oxygen consumed by reaction (8) until $3 \mathrm{~min}$ from silicon addition is estimated as at most $25 \mathrm{ppm}$ by the comparison of the increase of the dissolved oxygen content observed in this experiment with that obtained in the previous work. ${ }^{15)}$

C. E. Sims suggested the formation of the suboxide such as $\mathrm{SiO},{ }^{16)}$ but the formation of such oxide deviated in composition markedly from the stable oxide seems very improbable.

In the preceding section, the dissolved oxygen content was calculated by assuming the deoxidation product to be silica. The error in calculation due to this assumption is, however, regarded as negligibly small.

\section{IR Spectra of the Extracted Residue and Replacement Reaction}

As mentioned above, considerably large amounts of $\mathrm{SiO}_{x}$ is considered to exist in the deoxidized melt with a fraction of which remained very small in size. Consequently, the presence of $\mathrm{SiO}_{x}$ must be confirmed indirectly by some appropriate means. The following section will describe experiments directed towards this problem.

\section{IR Spectra of the Extracted Residue}

In Fig. 11 are shown, as an example, the infra-red absorption spectra of the residue extracted from the samples which were taken at suitable intervals after $0.1 \%$ silicon addition. The residue from the equilibrium sample shows three absorption bands at 1100 , 800 and $475 \mathrm{~cm}^{-1}$ characteristic of vitreous silica. ${ }^{17,18)}$ These bands are assigned respectively to $\nu_{3}, \nu_{1}$ and $\nu_{4}$ vibrations of $\mathrm{SiO}_{4}$ tetrahedron. On the other hand, the residue from the initial stage of the deoxidation process shows, besides the above three bands, three broad shoulders at about 1200,1030 and $430 \mathrm{~cm}^{-1}$. The appearance of these shoulders suggests that some constituents different from silica in composition and structure are contained in the residue. This observation is considered as a positive evidence for the presence of $\mathrm{SiO}_{x}$ in the melt.

F. Honda, et al. and H. Matsumoto, et al. confirmed the presence of considerable amount of $\theta-, \delta$ - and $\kappa$ alumina which are stable at low temperature, other than $\alpha$-alumina, in the samples taken in the initial stage of the aluminium deoxidation. ${ }^{19,20)}$ These oxides are likewise looked upon as the one that $\mathrm{Al}_{x} \mathrm{O}_{y}$ $(x \mid y>2 / 3)$ formed by aluminium addition was frozen in solidified sample through a compositional change during solidification.

\section{Replacement Reaction}

The replacement reaction is expected to take place to an appreciable extent between very fine $\mathrm{SiO}_{x}$ and silicon and oxygen dissolved in the melt. The progress of this reaction can be examined by utilizing radioactive silicon. To this purpose, small amount 


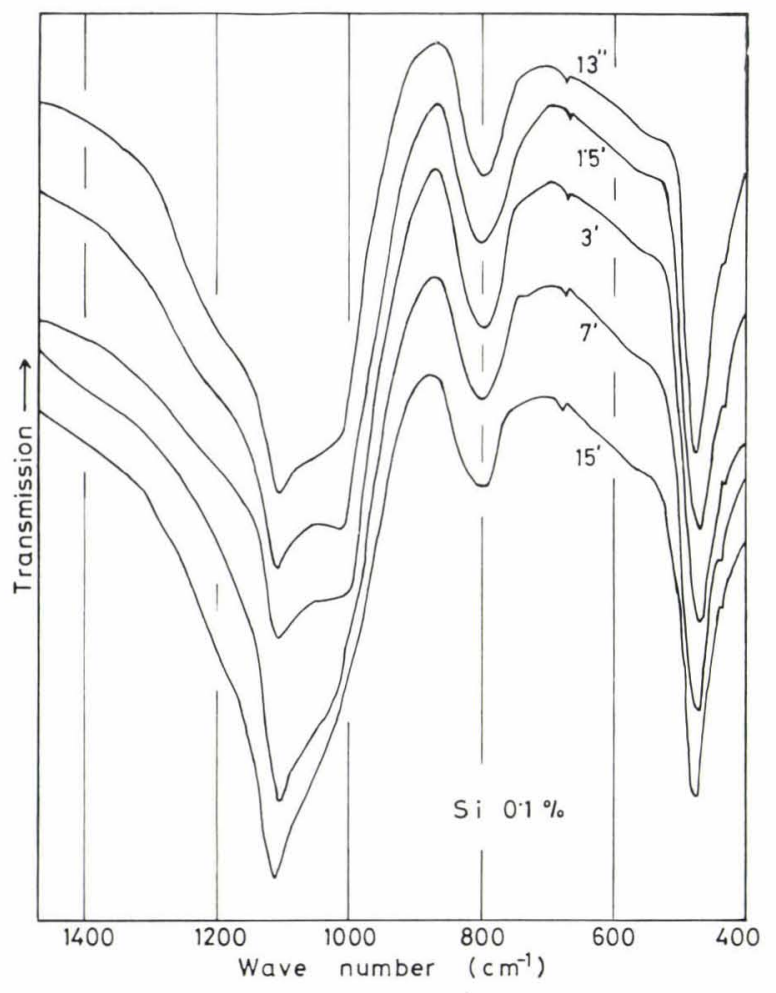

Fig. 11. Infra-red absorption spectra of the residues extracted from the samples which were taken at suitable intervals after $0.1 \%$ silicon addition

of radioactive silicon $(0.023$ or $0.013 \%$ ) was added to the melt at $25 \mathrm{sec}$ after $0.42 \%$ silicon deoxidation and samples were taken at suitable intervals after addition of radioactive silicon.

Figure 12 shows the changes in the radioactivity of the inclusion contained in $1 \mathrm{~g}$ iron melt which was kept at $1600^{\circ} \mathrm{C}$ in silica crucible. The radioactivity increased up to $1 \mathrm{~min}$, then decreased to reach a constant value in about $10 \mathrm{~min}$. The appearance of a maximum on the radioactivity $v s$. time plot is due to the circumstances that the amount of the radioactive product increases at first with the progress of the replacement reaction, while it decreases with time owing to the successive separation of the product from iron melt. The constant radioactivity after $10 \mathrm{~min}$ indicates also that the replacement reaction scarcely takes place between the crucible wall and silicon dissolved in the melt.

From such observation, it is considered that (1) a large number of invisibly small products are formed in iron melt by silicon addition, and (2) they decrease, however, gradually with time and almost separate from the melt when equilibrium is established.

The major problem in the determination of the dissolved oxygen content by the use of radioactive silicon is thus the influence of the replacement reaction taking place during solidification of sample. However, the influence seems negligibly small in the present experiment with the aid of rapid cooling of the taken sample. The fair agreement between the dissolved oxygen contents obtained in the repeated runs where the charged amount of radioactive silicon was changed supports this argument.

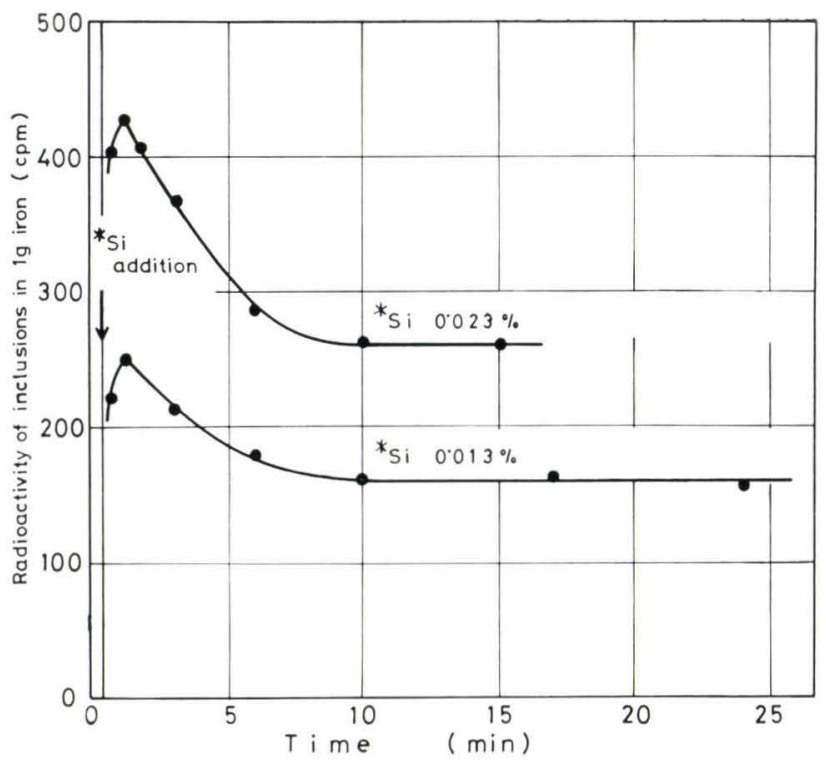

Fig. 12. Changes of the radioactivity of the residue extracted from $1 \mathrm{~g}$ sample. Small amount of radioactive silicon was added at $2.5 \mathrm{sec}$ after $0.42 \%$ silicon addition.

\section{Silicon Deoxidation in Alumina or Magnesia Crucible}

The dissolved oxygen content first decreased rapidly, and reaching a minimum, increased gradually. After attaining a maximum at about $4 \mathrm{~min}$, however, it decreased again to reach a constant value in about $15 \mathrm{~min}$.

The first rapid decrease of the dissolved oxygen content is due to the same mechanism as explained for the deoxidation in a silica crucible. The subsequent increase is, however, considered to be the consequence of the transfer of oxygen absorbed on the crucible wall, at least in the early period of the increase :

$$
\mathrm{O}\left(\mathrm{Al}_{2} \mathrm{O}_{3}, \mathrm{MgO}\right) \rightarrow \underline{\mathrm{O}}
$$

After the crucible wall has been coated with silica by adhesion of the deoxidation product, the increase is mainly caused by the reaction $\mathrm{SiO}_{2} \rightarrow \underline{\mathrm{Si}}+2 \underline{\mathrm{O}}$.

The second slow decrease of the dissolved oxygen content is likely to be due to the reaction $\underline{\mathrm{S}}+2 \underline{\mathrm{O}} \rightarrow$ $\mathrm{SiO}_{2}$ taking place as a result that the amount of adhesion of the deoxidation product becomes smaller, and correspondingly the activity of silica at the crucible wall decreases gradually with the progress of the slagging reaction between the crucible material and the deoxidation product. The agreement between the results obtained in alumina and magnesia crucibles suggests further that the materials of these crucibles used in the present experiment scarcely influence the rate of the oxygen transfer from the crucible into the melt or the change in the activity of silica with the slagging reaction.

In the case of the silicon deoxidation of the quasistatic melt in an alumina crucible, the dissolved oxygen content changes in a similar manner as in the case of the stirred melt. The sluggishness of the change compared to the stirred melt is considered that the 
process of the oxygen transfer is rate-controlled in this case by the diffusion of silicon or oxygen from the crucible wall into the melt.

\section{Conclusion}

The change of the dissolved oxygen content with time after silicon deoxidation was determined by utilizing radioactive silicon. The dissolved oxygen content first decreased rapidly below the equilibrium value, and reaching a minimum, increased gradually either to the equilibrium value (silica crucible) or, after attaining a maximum, decreased again to reach a constant value (alumina or magnesia crucible).

The mechanism of the silicon deoxidation was discussed on the basis that such results were attributable to the nonuniform distribution of silicon and the formation of $\mathrm{SiO}_{x}(x<2)$ in the melt immediately after silicon addition.

The conclusions obtained are summarized as follows:

(1) In the region of high silicon content, $\mathrm{SiO}_{x}$ $(x<2)$ is formed in the melt, because of the exceedingly fast rate of reaction between silicon and oxygen.

(2) The minimum oxygen content attained immediately after silicon addition corresponds to the average oxygen content at the time when silicon, oxygen and deoxidation product have been uniformly distributed throughout the melt.

(3) Very fine $\mathrm{SiO}_{x}(x<2)$ is considered to suspend in the deoxidized melt until the last stage of the deoxidation process. The replacement reaction proceeds to a considerable extent between such fine oxide and dissolved silicon and oxygen.

(4) Oxygen takes part in the processes of growth of the deoxidation products and adhesion of them to the crucible wall.

(5) The deoxidation process in the stirred melt is rate-controlled by the rate of the reaction:

$$
\mathrm{SiO}_{2} \rightarrow \underline{\mathrm{Si}}+2 \underline{\mathrm{O}} \text {. }
$$

(6) $\mathrm{SiO}_{x}(x<2)$ is not widely different from silica in composition.

(7) In the case of alumina or magnesia crucible, the dissolved oxygen content decreases again after attaining a maximum, owing to the decrease in the activity of silica at the crucible wall.

\section{Acknowledgements}

The authors wish to express their thanks to Professors T. Ototani, T. Fuwa, M. Ohtani and S. Banya, and Assistant Professors R. Ohno and N. Matsumoto of Tohoku University for their stimulating discussions and helpful suggestions. They also wish to express their thanks to Professor S. Suzuki and Assistant S. Mitsugashira of Tohoku University for their kind guidance and assistance to the radiochemical measurement.

\section{REFERENCES}

1) T. Sasai and R. Sakagami: Tetsu-to-Hagané, 62 (1976), 798.

2) Y. Miyashita: Tetsu-to-Hagané, 52 (1966), 13.

3) I. Miura, K. Suga and T. Matano: Measurement of Radiant Ray, Shokabo, Tokyo, (1953).

4) T. Ito: Technique in the Experiment Using Isotope, Chijinshokan, Tokyo, (1962).

5) C. A. Duckwitz, E. Förster and H. Richter: Arch. Eisenhüttenw., 39 (1968), 333.

6) A. Fischer and C. Pieper: Arch. Eisenhüttenw., 44 (1973), 251.

7) V.I. Yavoiskii: Stal', 3 (1970), 228.

8) L. E. Rohde, A. Choudhurry and M. Wahlster: Arch. Eisenhüttenw., 42 (1971), 165.

9) O. Yanagisawa and M. Maruyama: Bull. Japan Inst. Metals, 14 (1975), 29.

10) E. Förster, W. Klapdar and H. Richter: Arch. Eisenhüttenw., 45 (1974), 405.

11) P. M. Mathew, M. L. Kapoor and M. G. Frohberg: Arch. Eisenhüttenw., 43 (1972), 865.

12) K. Kumai, H. Matsunaga, T. Saeki and K. Asano: Tetsuto-Hagané, 60 (1974), 1310.

13) J. Chipman: Trans. AIME, 224 (1962), 1288.

14) A. A. Vertman: The First Japan-USSR Joint Symposium on Physical Chemistry of Metallurgical Processes, ISIJ, (1967), 126.

15) R. Sakagami and T. Sasai: Tetsu-to-Hagané, 57 (1971), 2197.

16) C. E. Sims: Trans. AIME, 215 (1959), 359.

17) I. Simon and H. O. McMahon: J. Chem. Phys., 21 (1953), 23.

18) J. Reitzel: J. Chem. Phys., 23 (1955), 2407.

19) F. Honda and K. Hirokawa: Tetsu-to-Hagané, 60 (1974), 2013.

20) H. Matsumoto, Y. Hirooka, S. Koyama, K. Narita and M. Hiraiwa: Tetsu-to-Hagané, 59 (1973), '73-A101. 